\title{
Perceived religious discrimination as predictor of work engagement, with specific reference to the Rastafari religion
}

\begin{tabular}{|c|c|}
\hline \multicolumn{2}{|c|}{$\begin{array}{l}\text { Authors: } \\
\text { Freda van der Walt }{ }^{1} \\
\text { Thulo S. Mpholo } \\
\text { Petronella Jonck }{ }^{2}\end{array}$} \\
\hline \multicolumn{2}{|c|}{$\begin{array}{l}\text { Affiliations: } \\
{ }^{1} \text { Department of Human } \\
\text { Resources Management, } \\
\text { Central University of } \\
\text { Technology, South Africa }\end{array}$} \\
\hline \multicolumn{2}{|c|}{$\begin{array}{l}{ }^{2} \text { Research and Innovation } \\
\text { Unit, National School of } \\
\text { Government, South Africa }\end{array}$} \\
\hline \multicolumn{2}{|c|}{$\begin{array}{l}\text { Corresponding autho } \\
\text { Freda van der Walt, } \\
\text { fvdwalt@cut.ac.za }\end{array}$} \\
\hline \multicolumn{2}{|c|}{$\begin{array}{l}\text { Dates: } \\
\text { Received: } 28 \text { Aug. } 2015 \\
\text { Accepted: } 01 \text { Feb. } 2016 \\
\text { Published: } 25 \text { May } 2016\end{array}$} \\
\hline \multicolumn{2}{|c|}{$\begin{array}{l}\text { How to cite this article: } \\
\text { Van der Walt, F., Mpholo, T.S. } \\
\text { \& Jonck, P., 2016, 'Perceived } \\
\text { religious discrimination as } \\
\text { predictor of work } \\
\text { engagement, with specific } \\
\text { reference to the Rastafari } \\
\text { religion', Verbum et Ecclesia } \\
37(1) \text {, a1524. http://dx.doi. } \\
\text { org/10.4102/ve.v37i1.1524 }\end{array}$} \\
\hline \multicolumn{2}{|c|}{$\begin{array}{l}\text { Copyright: } \\
\text { (C) 2016. The Authors } \\
\text { Licensee: AOSIS. This } \\
\text { is licensed under the } \\
\text { Creative Commons } \\
\text { Attribution License. }\end{array}$} \\
\hline \multicolumn{2}{|l|}{ Read online: } \\
\hline 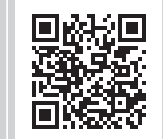 & $\begin{array}{l}\text { Scan this QR } \\
\text { code with your } \\
\text { smart phone or } \\
\text { mobile device } \\
\text { to read online. }\end{array}$ \\
\hline
\end{tabular}

Although perceived religious discrimination has been studied in the past, much remains unknown about the topic. The focus of this study was the Rastafari religion, because this religious group has up to now been excluded from research studies. A cross-sectional descriptive study was conducted with a sample of 80 employees belonging to the Rastafari religion, chosen from organisations in two provinces in South Africa. The findings emanating from the quantitative research study indicated that, on average, the respondents perceived to be discriminated against. Furthermore, a positive relationship was established between perceived religious discrimination and work engagement. These findings advanced the understanding of perceived religious discrimination, and the impact that it may have on work engagement, particularly with reference to the Rastafari religion.

Intradisciplinary and/or interdisciplinary implications: The article contributes to the interdisciplinary discourse regarding perceived religious discrimination, with specific reference to the Rastafari religion which is a minority religious group in South Africa. Perceived religious discrimination is discussed and investigated in the context of the workplace, and the aim was to establish whether perceived religious discrimination influences work-related attitudes, such as work engagement. Because previous studies have associated perceived discrimination with less job involvement and career satisfaction, fewer career prospects, greater work conflict, lower feelings of power, decreased job prestige, and less organisational citizenship behaviour (Thomas 2008:80), it was expected that perceived religious discrimination would have a negative influence on work engagement. The findings show that religion possibly provides individuals with the necessary personal resources to persevere when faced with religious discrimination, and sustain performance as well as attain success within the context of the workplace.

\section{Introduction}

Despite the fact that workplaces in South Africa are highly regulated, discrimination persists, and it is a reality for many employees. Marumoagae (2012) asserts that inequality, discriminatory practices, and lack of transformation are still the greatest challenges that most employees are faced with in the South African labour market. The South African Constitution and various labour laws provide protection against violation of human rights, and, by extension, discrimination. However, this regulatory framework, in itself, cannot prevent the occurrence of discriminatory practices. Although many organisations seem to adhere to these legislative requirements, rules and regulations are not necessarily adhered to by organisational members, hence the continued prevalence of discriminatory practices.

An individual is discriminated against when they are denied privileges or rights (Grogan 2011). Thus, discrimination deprives an individual of the right to adequate protection and development or advancement (Jonck, Le Roux \& Hoffman 2012). Employees become victims of discrimination if they are singled out for prejudicial treatment based on an inherent characteristic, such as their religion. Compared to other forms of discrimination, such as racial and gender discrimination, religious discrimination seems to be less prevalent in the workplace. However, international statistics show that religious discrimination cases have doubled over the past 15 years, and that the incidence of religious discrimination has increased disproportionately to other forms of discrimination (Trottman 2013).

In terms of South Africa's Constitution, religious discrimination is prohibited in South African workplaces. Section 9(2) of the Constitution of the Republic of South Africa, Act 108 of 1996 (RSA 1996) states that no person may unfairly discriminate directly or indirectly against 
anyone on one or more grounds, including race, gender, sex, pregnancy, marital status, ethnic or social origin, colour, sexual orientation, age, disability, religion, conscience, belief, culture, language, and birth. In the workplace, the Constitution is given effect via labour legislation, specifically the Employment Equity Act (EEA), Act 55 of 1998 (RSA 1998), and the Labour Relations Act (LRA), Act 66 of 1995 (RSA 1995). In this regard, Section 6(1) of the EEA (RSA 1998) prohibits unfair discrimination, whether directly or indirectly, against an employee in any employment policy or practice on grounds including race, gender, pregnancy, marital status, family responsibility, ethnic or social origin, colour, sexual orientation, age, disability, religion, HIV status, conscience, belief, political opinion, culture, language, and birth. Furthermore, Section 187(1) of the LRA (RSA 1995) stipulates that unfair discrimination on the basis of religion leading to dismissal will automatically be regarded as an unfair dismissal.

Opposing views exist regarding religion and the workplace, and the expression of religion in the workplace. Some argue that religion, and the expression thereof, in the workplace is inappropriate, and that it generates strong opinions (Webley 2011). In contrast to this view, others state that employees cannot be divorced from their religious beliefs, and that employers therefore need to deal with religion in a sensitive manner, and that if they do so, this can lead to them becoming employers of choice (Mitchell, as cited in Webley 2011). Thus, regardless of one's views on the matter, religion seems to be a contentious issue, which cannot be ignored by organisations, as religion is deeply ingrained in individuals, and it may potentially influence employees' attitudes, and consequently their behaviour.

Religious discrimination has been largely neglected in academic research. However, other forms of perceived discrimination have been studied in relation to positive work-related attitudes and organisational outcomes. As such, perceived discrimination has been found to be an antecedent of work-related outcomes such as work-related attitudes, career advancement, and conflict (Riordan, Schaffer \& Steward 2005). Tesfaye (2010) studied the above, and found that although fair treatment does not have an effect on job satisfaction and job performance, unfair treatment affects the work environment negatively. Ensher, Grant-Vallone and Donaldson (2001) found that perceived discrimination affects work-related attitudes such as organisational commitment, job satisfaction, and organisational citizenship behaviour.

Another study confirming the relationship between perceived discrimination and work-related attitudes found that perceived ethnic discrimination was negatively related to job satisfaction, affective commitment, and organisational citizenship behaviour (Jagusztyn 2010). Based on these associations which have been established, one may predict that a negative relationship will exist between perceived religious discrimination and a work-related attitude such as work engagement. Thus, although previous studies have determined the effect of perceived discrimination on work-related attitudes and individual behaviour, there is a paucity of studies that have focused on religious discrimination in the workplace. Furthermore, in the South African context, the relationship between perceived religious discrimination and work-related outcomes has not been investigated. In light of the above, the aim of the study was to determine the influence of perceived religious discrimination on work engagement, with specific reference to the Rastafari religion.

\section{Contextualising the study}

The Rastafari movement originated from a complete rejection of the British imperial culture that dominated Jamaica's colonial society in the 18th century, in which a determined effort was made to fashion an identity that was based on reappropriation of an African heritage (Campbell 1985). The religion identified with the ancient symbolism of Zion and Babylon, representing good and evil, respectively (Thompson 2012). Babylon is regarded as both 'the embodiment of evil in biblical literature' and 'a symbol of bondage, not only for ancient Israelites, but for all humanity held in slavery and oppression, especially black people' (Murrell \& Williams, as cited in Thompson 2012:332). It was further believed that the black people of Africa (the 'Israelites', or 'holy people') have been punished by God for their sins, through slavery under white people (Thompson 2012). The Rastafari religion was inspired by the seminal works and philosophy of Marcus Mosiah Garvey, a Jamaican black nationalist (Barnett 2012). In the late 1920s, Marcus Garvey prophesied the coronation of an African king to carry forward his prophesies (Barnett 2012). In 1930, Ras Tafari was identified as that African king by Garvey's followers, who now adopted 'Rastafari' as the name of the movement (Barnett 2012:172). It is believed that Haile Selassie I was the 225th restorer of the Solomonic dynasty, representing one of the oldest thrones on earth (Chawane 2012). The coronation of Haile Selassie I affirmed the independent place of Rastafari in Judaeo-Christian religions (Chawane 2012).

The Rastafari movement received much support in Africa, mainly because Haile Selassie I was a black emperor of virtually the only African nation that had successfully resisted colonialism (Chawane 2012). The African continent is of particular importance to the Rastafari movement, and is considered the Holy Land, Zion, the Garden of Eden, and the cradle of mankind and human civilisation referred to in the book of Genesis, and God's chosen place on earth (Barnett 2014). The Rastafari movement created hope for an oppressed race on the African continent. In fact, the Rastafari movement has been regarded as one of the foundation forces in the struggle for dignity, emancipation, and unity of Africans (Campbell 1985).

The general public in South Africa was first made aware of the existence of the Rastafari movement in the context of work when an employee was killed during a strike action in Uitenhage and was referred to as a 'Rasta' by media reports (Chawane 2012:172). Subsequent to this, two landmark cases 
involving Rastafari have increased public awareness of this religious group, namely the infamous case of Prince v President of the Law Society of the Cape of Good Hope and Others (2001) CCT36/00, and the case of the Department of Correctional Services and Another v Popcru and Others (2010) CA 6/2010. The cases mentioned above led to much controversy, and it became apparent that religious freedom and the practices of different religions remain contentious issues in South Africa's new democratic society, and ultimately the labour market. Because of the outward manifestation of the Rastafari religion, this group may be particularly vulnerable to unfair discrimination in the workplace. Furthermore, the public awareness that has been generated regarding Rastafari has not always been favourable, which may lead to this religious group being discriminated against in the workplace. Against the background described above, the question arises as to whether followers of the Rastafari movement perceive being discriminated against, and how this perceived discrimination influences their attitude towards the workplace, and specifically their work engagement.

\section{Theoretical framework}

Various theories can be used to explain religious discrimination in the workplace, such as the contact theory, the religious stratification theory, and the cultural distance theory. For the purposes of this study, social identity theory (SIT) was used as theoretical underpinning. SIT, developed by Henri Tajfel (1972), was premised on the assumption that the group that an individual belongs to is an integral source of pride and self-esteem, and that this group also provides the individual with a sense of belonging, or an identity (Tajfel 1972). The SIT defined social identity as 'the individual's knowledge that he or she belongs to a certain social group' (Tajfel 1972). Social interaction within the reference group is perceived as mutually beneficial, providing emotional and value significance (Jonck et al. 2012:94). The group an individual belongs to is referred to as the in-group, whereas all other groups are referred to as out-groups. This distinction between groups is often the primary source of prejudice, discrimination, and conflict (Hewstone, Rubin \& Willis 2002). This is mainly because in-group members perceive other ingroup members more favourably, and out-group members less favourably. In South Africa, religious groups that are not European or Caucasian are often marginalised and relegated as the 'other' (Amien 2006).

Social identity consists of the cognitive, emotional, and evaluative aspects of an individual's self-concept, which are derived from social group membership that is salient to the individual (Tajfel \& Turner 1979). Accordingly, individuals that share membership in a certain social category constitute the in-group, whereas all other individuals belong to the outgroup. In addition, an individual may belong to numerous social groups concurrently, and these affiliations can have an effect on how different groups perceive, feel (see e.g., Cottrell \& Neuberg 2005; Fiske et al. 2002; Gordijn, Wigboldus \& Yzerbyt 2001), and behave (see e.g., Bushman \& Bonacci 2004) in social interactions (Tajfel \& Turner 1979).
Groups can be defined based on nationality, gender, age, race, or religious affiliation. Thus, intergroup bias is an umbrella concept and scientific construct that incorporates different behaviours, cognitions, and attitudes along group lines that are more favourable towards in-group members than they are towards out-group members (Hogg \& Abrams 1988). These behaviours, cognitions, and attitudes constitute stereotypes, prejudices, and discrimination (Bodenhausen \& Richeson 2010), also referred to as 'group antagonism' (Jonck et al. 2012). Subtle and perceived discrimination is likely to result from actions that are ambiguous but still attributed to group status. Turner (1983) emphasised that social categorisation alone is sufficient for intergroup discrimination. Hogg and Abrams (1988) held a similar view, and stated that social categorisation and discontinuous classification of individuals into two distinct groups is sufficient to generate intergroup discrimination. Thus, imposing social categorisation upon people, even on an explicitly random basis, produces discriminatory intergroup behaviour. Similarly, Wilder (1986), elaborating on a review paper, indicated that the mere categorisation of individuals into an in-group and an out-group is sufficient to create bias.

Therefore, in a work setting, employees that are demographically different from their colleagues may feel uncomfortable because of the recognition that their social identity is dissimilar to those with whom they interact on a daily basis, which may result in differential treatment and ultimately the possibility of discrimination. It is postulated that because of differences in religious affiliation, the ingroup may react to the out-group, by engaging in actions such as stereotyping, bias, and prejudiced behaviour. This, in turn, may lead to differential treatment, and although differential treatment does not necessarily constitute discrimination, it may lead to the out-group perceiving that they have been discriminated against. It is postulated that perceived discrimination will have a negative influence on the out-group's work engagement, which, in turn, will negatively affect organisational effectiveness and competitive advantage.

\section{Defining key concepts}

Religious discrimination can be defined as constraints placed on the religious practices of minority groups in a state that are not placed on the religious practices of the majority religion (Fox 2007). As was indicated earlier, the study investigated perceived discrimination, which refers to the behavioural manifestation of a negative attitude or judgement, or unfair treatment, as perceived by a religious group. Although religious discrimination may be considered a subset of general discrimination against minorities, it is arguably significant and theoretically distinct. It is asserted that religious discrimination is more deeply rooted than other forms of discrimination, such as gender discrimination (Akbaba \& Fox 2011). Factors that may contribute to religious discrimination include legal ambiguities, increased religious diversity in the country's workforce, increased expression of religious beliefs, the unique nature of a religion compared to 
other protected categories, and individual differences such as stigma consciousness and system justification beliefs (Ghumman et al. 2013).

Fox (2007) identified a number of potential incentives for religious discrimination, as well as factors that may influence the level of religious discrimination. The aforementioned includes, for example, countries with an official religion that the majority adheres to, and which give legitimacy or preference to some religions over others. In addition, when national and ethnic minorities are perceived as challenges or threats to the state, religious traditions which have different understandings or conceptions of human rights may be perceived as contributing factors to religious discrimination (Fox 2007). Furthermore, minorities with a longer presence in a particular country are generally considered more legitimate, whereas religious minorities that are new to a country may be perceived as unorthodox, or more foreign, and, hence more of a threat than established minority religious groups (Akbaba \& Fox 2011). Consequently, it is hypothesised that Rastafarians may experience an elevated level of perceived religious discrimination because the Rastafari religion is not the official religion of South Africa, but a minority religion, and it has not been present in the country for a very long time.

When conceptualising the concept of work engagement, it is necessary to distinguish between the various perspectives that have been offered. Kahn (1990:694) first defined engagement at work as 'the harnessing of organisation members' selves to their work roles', and explained that in engagement, 'people employ and express themselves physically, cognitively, and emotionally during role performances'. Maslach and Leiter (as cited in Chughtai \& Buckley 2008), subsequently proposed a more comprehensive view, asserting that engagement is characterised by energy, involvement, and efficacy. They further asserted that work engagement is the opposite of burnout (Chughtai \& Buckley 2008). According to their interpretation of work engagement, an individual that is experiencing burnout will experience exhaustion, as opposed to energy; cynicism, as opposed to involvement; and ineffectiveness, as opposed to efficacy (Chughtai \& Buckley 2008).

Another perspective of work engagement is based on the work of Schaufeli et al. (2002), who view work engagement and burnout as two concepts that are related but independent (Kassing et al. 2012). Thus, an employee may experience high levels of absorption, but will not necessarily experience burnout. In line with this perspective of work engagement, Schaufeli, Taris and Bakker (2008) define work engagement as:

a positive, fulfilling, work-related state of mind that is characterised by vigour (i.e. high levels of energy and mental resilience while working, the willingness to invest effort in one's work, and persistence also in the face of difficulties), dedication (i.e. a sense of significance, enthusiasm, inspiration, pride, and challenge), and absorption (i.e. being fully concentrated and engrossed by one's work whereby time passes quickly and one has difficulties with detaching oneself from work). (p. 176)

For the purposes of this study, the latter definition of work engagement will be adopted. The rationale for this choice of definition is that it confirms that work engagement is an independent construct consisting of a physical, a cognitive, and an emotional dimension (Nelson \& Quick 2006). Furthermore, the Utrecht Work Engagement Scale was used to measure work engagement, which is based on the above definition of work engagement.

Work engagement consists of three dimensions, namely vigour, dedication, and absorption (Schaufeli et al. 2008). Vigour refers to high mental resilience and high levels of energy in the workplace, clear and conscientious efforts to devote oneself to one's work, and persistence when facing difficulties or failure (Kassing et al. 2012). Goosen (2011) asserted that employees with high levels of vigour will execute their work with energy, zest, and stamina, whereas employees with low levels of vigour will have diminished capacity. Scholars that view work engagement as the opposite of burnout maintain that vigour may be regarded as the opposite of exhaustion, which is a dimension of burnout (Kassing et al. 2012). As was indicated in the previous paragraph, dedication is characterised by a strong sense of identification with one's work, and it includes feelings such as significance, enthusiasm, inspiration, pride, and challenge (Chughtai \& Buckley 2008). Goosen (2011) postulated that employees that have high levels of dedication strongly identify with their work, because they experience it as meaningful, inspiring, and challenging, which creates a sense of pride in and enthusiasm for their work.

Scholars that view work engagement as the opposite of burnout assert that dedication may be regarded as the opposite of cynicism, which is a dimension of burnout (Kassing et al. 2012). Absorption refers to an employee's attentiveness to their work, and being engrossed in their work to the extent that they find it difficult to detach from their work (Schaufeli et al. 2008). Thus, an employee that is absorbed in their work feels that time is passing rapidly. Unlike the other two dimensions of work engagement (i.e. vigour and dedication), which are viewed as the opposite of certain dimensions of burnout, absorption is not seen as the opposite of a lack of professional efficacy (which is a dimension of burnout). Goosen (2011) asserted that an employee with high levels of absorption will feel happily engrossed in and immersed in their work and will have difficulty detaching from it.

There are two main antecedents of work engagement, namely job resources and personal resources (Bakker, Albrecht \& Leiter 2011). Personal resources are defined as:

an individual's positive psychological state of development, characterised by having confidence (self-efficacy) to take on and put in the necessary effort to succeed in challenging tasks, making a positive attribution (optimism) about succeeding now and in the future, persevering towards goals, and when necessary, redirecting paths to goals (hope) in order to succeed, and when beset by problems and adversity, sustaining and bouncing back and even beyond (resilience) to attain success. (p. 7)

Job resources, on the other hand, refer to supervisory support, innovativeness, information, appreciation, and organisational 
climate (Rice 2009). Other scholars define job resources as physical, social, or organisational aspects of the job that may reduce job demands and the associated physiological and psychological costs (Schaufeli \& Bakker, as cited in Sibisi 2012). Sonnentag (2011) postulates that work engagement can likewise be influenced by task-related aspects, which refer to specific features of a task.

Work engagement has been found to be negatively related to intention to quit, and positively related to job satisfaction and organisational commitment (Schaufeli et al. 2008). In a study by Kassing et al. (2012), work engagement was investigated in relation to employee dissent (i.e. the expression of disagreement or contradictory opinions about organisational policies and practices). The findings indicate that dissent expression is related to work engagement, particularly dissent expressed towards management and co-workers.

It has been suggested that in order to experience life satisfaction, an individual needs to be passionate and enthusiastic about their daily tasks in both their personal and their work domains (Williamson 2011). Calitz (2013) asserted that employees that are engaged in their work are likely to perform well, and to experience positive health and positive emotions. It has also been suggested that engaged employees are better equipped to address issues in the workplace such as stress and change (Rice 2009). In addition, employees that experience work engagement are more driven, and are key role players in helping to move the organisation forward (Krueger \& Killham, as cited in Rice 2009).

Several researchers have explored the concept of perceived discrimination and its effects on different factors. Gee, Pavalko and Long (2007) examined a sample of mature-aged US women, and they found that perceived discrimination had significant adverse effects on health outcomes. Richman et al. (2010) undertook a meta-analysis of the health effects of perceived discrimination, and they similarly concluded that perceived discrimination has a negative effect on both mental and physical health. Previous research has also associated perceived discrimination with less job involvement and career satisfaction, fewer career prospects, greater work conflict, lower feelings of power, decreased job prestige, and less organisational citizenship behaviour (Thomas 2008). Thus, because past research has found associations between perceived discrimination and various work-related attitudes, it is postulated that similar results will be obtained in this study, which investigates the relationship between perceived religious discrimination and work engagement for a South African sample. The objectives of this study are twofold, namely (1) to determine the extent to which a Rastafari sample perceives to be discriminated against because of its religious affiliation, and (2) to determine the influence of perceived religious discrimination on work engagement for a Rastafari sample.

\section{Problem statement}

The Rastafari religious group has not been studied before in the context of the workplace. Furthermore, South Africa is generally perceived as a religious society, with a population that has strong religious convictions (Van der Walt 2007). This suggests that religion is an imperative area of inquiry in the South African context. Previous studies investigating discrimination in the South African context have focused mainly on gender discrimination (e.g. Mxhakaza 2011), racial discrimination (e.g. Moifo 2012), discrimination against people with disabilities (e.g. Harmse-Truter 1998), discrimination against people living with HIV and AIDS (e.g. Chipangura 2013), and age discrimination (e.g. Walt 2002). It would also seem that only a few studies have focused on religious discrimination, and the majority of these studies have been social-psychological in nature (e.g. Jasperse, Ward \& Jose 2012). In light of the above, one may conclude that religious discrimination in the context of the workplace has not been sufficiently investigated from an organisational-behaviour perspective in the South African context, and particularly in terms of minority religious groups. For this reason, it is important to determine whether perceived religious discrimination predicts work-related attitudes, particularly because negative attitudes may potentially have a negative impact on employee behaviour, and ultimately organisational effectiveness and competitiveness. Against this background, the research hypothesis for the study was formulated as follows: 'Religious discrimination as perceived by a Rastafari sample statistically significantly influences work engagement negatively'.

\section{Research methodology Research design}

A cross-sectional descriptive quantitative research design was used, because the research was carried out at a specific point in time on a Rastafari sample. The current study was descriptive in nature, in that the aim of the study was to describe a phenomenon as accurately as possible in a specific target population (Salkind 2012). According to Horn (2009), quantitative research collects mainly numerical data and opinions, and often relies on deductive reasoning. In terms of the stated research hypothesis, a quantitative research design was deemed necessary to statistically significantly determine whether the variance in work engagement could be attributed to perceived discrimination.

\section{Measuring instruments}

Primary data were collected by means of self-administered questionnaires which consisted of closed-ended questions. Perceived religious discrimination was measured using selfrating items. This section was measured on a four-point Likert-scale, with possible responses being 'definitely yes', 'yes', 'no', and 'definitely not'. Typical questions included in the questionnaire were 'Have you ever been harassed by someone at work because you are a Rasta?' and 'Have you ever been denied an opportunity in the workplace because you are a Rasta?' The perceived discrimination section of the questionnaire had an internal consistency of 0.81 , as measured by a Cronbach's alpha coefficient. The theoretical mean of the subsection measuring perceived religious discrimination was $75 \%$. As the questions in this subsection of the questionnaire were stated negatively, they were rephrased positively before the statistical analysis was conducted. 
Work engagement was measured using the Utrecht Work Engagement Scale (UWES). The UWES measures work engagement, as well as the three dimensions thereof, namely vigour, dedication, and absorption. This measuring instrument consists of 17 questions, measured on a sevenpoint Likert-scale, with possible responses ranging from 'never' (0) to 'always' (6). The internal consistency of the UWES, as measured by a Cronbach's alpha coefficient, was 0.95. Storm (2002:60) reported Cronbach's alpha coefficients of between 0.68 and 0.91 for the subscales of the UWES for a South African sample. Salkind (2012) asserted that a correlation coefficient of between 0.8 and 1.00 can be regarded as very strong. Thus, both measuring instruments used in the study had very good correlation coefficients, and they may be regarded as reliable instruments to measure work engagement and perceived religious discrimination for the current sample. The theoretical mean for the UWES was $83.3 \%$.

\section{Population and sample}

Snowball sampling was used to generate the sample, in that Rastafari that were working in two provinces in South Africa were approached, based on referrals, to participate in the study. No official data is available to determine the size of the population investigated in the study. In total, 80 Rastafari were included in the sample. An introductory letter was attached to the questionnaire, in which the aims and objectives of the study were clearly stated. In addition, the respondents were informed that participation was completely voluntary, and that they could withdraw from the study at any time. The respondents were also assured that they could complete the questionnaire anonymously, and that their information would be kept confidential.

The final sample consisted mostly of males $(63.8 \%)$, with the remainder of the sample being female (36.2\%). In terms of racial distribution, the overwhelming majority of the sample was African (96.3\%), followed by white respondents (2.5\%), and mixed race respondents (1.2\%). The majority of the sample was between the ages of 31 and $40(48.8 \%)$, followed by those between the ages of 21 and $30(26.3 \%)$, those between the ages of 41 and $50(21.2 \%)$, and those between the ages of 51 and 60 $(3.7 \%)$. The majority of the sample had been working between 1 and 10 years $(62.5 \%)$, followed by those who had 11 to 20 years of work experience (27.5\%), and those who had 21 to 30 years' work experience $(10 \%)$. The majority of the respondents had either a national diploma or a bachelor's degree $(58.7 \%)$, followed by those who had a postgraduate degree (33.8\%), and those who had a Grade 12 qualification (7.5\%). When asked about the strength of their religious conviction, the majority indicated that their religious conviction was very strong $(87.5 \%)$, followed by respondents that indicated that their religious conviction was relatively strong (12.5\%).

\section{Data analysis}

Data analysis was done by an independent research psychologist, using the Statistical Package for the Social Sciences (SPSS) version 20. The reliability of the measuring instrument was confirmed by determining a Cronbach's alpha coefficient. Quantitative data was analysed by means of a Pearson product-moment correlation and a multiple regression analysis. Descriptive statistical analyses were performed to determine the measures of central tendency, including the mean, the standard deviation, and minimum and maximum scores.

\section{Results}

The aim of the study was firstly to establish the extent to which a Rastafari sample perceived to be discriminated against because of their religious affiliation. Secondly, it was to determine the influence of perceived religious discrimination on work engagement. To achieve the first aim, the measures of central tendency were determined. They are depicted in Table 1.

As is evident from Table 1, the respondents reported to experience perceived religious discrimination $(\bar{x}=2.28$; $\mathrm{SD}=0.43499)$. With regard to work engagement, the respondents indicated that they were moderately engaged in their work $(\bar{x}=3.08 ; \mathrm{SD}=0.48982)$.

In order to determine whether perceived religious discrimination statistically significantly predicted work engagement, a Pearson product-moment correlation coefficient was performed, as a prerequisite to the multiple regression analysis. The results are indicated in Table 2.

The Pearson product-moment correlation results presented in Table 2 indicate that there was a statistically significant positive relationship between perceived religious discrimination and work engagement. According to these results, as perceived religious discrimination increases, work engagement increases. The strength of the relationship was medium to strong $(r=0.415)$. In order to determine how much of the variance in work engagement can be explained by perceived discrimination, a multiple regression analysis was performed. The results of this analysis are indicated in Table 3.

As is evident from Table 3, perceived religious discrimination statistically significantly predicted work engagement. It was found that $41.5 \%(\beta=0.415)$ of the variance in work engagement can be attributed to the experience of perceived religious discrimination.

TABLE 1: Measures of central tendency for the variables measured.

\begin{tabular}{lccccc}
\hline Variable & Minimum & Maximum & Median & $\bar{x}$ & SD \\
\hline $\begin{array}{l}\text { Perceived religious } \\
\text { discrimination }\end{array}$ & 1.5 & 3.38 & 2.13 & 2.28 & 0.43499 \\
Work engagement & 1.24 & 3.71 & 2.38 & 2.33 & 0.67543 \\
\hline
\end{tabular}

TABLE 2: Pearson's product-moment correlation results indicating the relationship between the different variables measured.

\begin{tabular}{lcc}
\hline Variable & $\begin{array}{c}\text { Perceived religious } \\
\text { discrimination }\end{array}$ & Work engagement \\
\hline Perceived religious discrimination & 1 & - \\
Work engagement & $0.4150 .000 * *$ & 1 \\
\hline
\end{tabular}

**, $p \leq 0.01$ 
TABLE 3: Multiple regression analysis results with work engagement as dependent variable and perceived discrimination as independent variable.

\begin{tabular}{lcccccccc}
\hline Variables & \multicolumn{8}{c}{ Perceived discrimination } \\
\cline { 2 - 9 } & $\boldsymbol{R}$ & $\boldsymbol{R}^{\mathbf{2}}$ & $\boldsymbol{F}$ & $\boldsymbol{B}$ & $\boldsymbol{t}$ & $\boldsymbol{P}$ & Tolerance & VIF \\
\hline Work engagement & 0.42 & 0.17 & 16.188 & 0.42 & 4.02 & $0.000^{* *}$ & 1 & 1 \\
\hline
\end{tabular}

$R, R$-value; $R^{2}, R$-squared value; $F, F$-value; $B$, Beta-value; $p$, significance; VIF, Variance Inflation Factor.

$* *, p \leq 0.01$

\section{Discussion and conclusion}

In terms of perceived religious discrimination, the respondents indicated that they perceive that they are being discriminated against because of their religious affiliation with the Rastafari religion (median $=2.13$; $\mathrm{SD}=0.43499$ ). This finding is consistent with previous reports of religious discrimination against Rastafari. Research conducted by Crozier-Fitzgerald (2010:1) highlights religious discrimination against Rastafari because of the outward manifestations of this religion, such as the wearing of dreadlocks. According to one of the respondents in the above-mentioned study, he had applied for more than 50 positions over a period of 4 years, but had been denied numerous opportunities because of his appearance, and hence because of his affiliation with the Rastafari religion (Crozier-Fitzgerald 2010:1). Similarly, Crocker, Major and Steele, as cited in Ghazarian (2008:24), suggest that individuals from ethnic minorities are likely to experience more discriminatory experiences, because of differences in outwardly visible individual characteristics. Thus, the research hypothesis formulated for this study is confirmed; that is, Rastafari do perceive to be discriminated against in the workplace because of their religious affiliation.

The results of the Pearson product-moment correlation (Table 2) show a strong positive correlation between perceived religious discrimination and work engagement $(r=0.415)$. In order to determine how much of the variance in work engagement (the dependent variable) can be explained by perceived religious discrimination (the independent variable), a multiple regression analysis was performed (Table 3). The results of the test show that perceived religious discrimination statistically significantly predicted work engagement. The Beta value $(\beta=0.415)$ explains that $41.5 \%$ of variance in work engagement can be attributed to the experience of perceived discrimination.

These results are not consistent with the findings of previous research regarding perceived discrimination. Although perceived religious discrimination has not previously been studied in relation to work engagement, Bayl-Smith and Griffin (2014) reported a negative relationship between perceived age discrimination and work engagement. However, as was indicated in the literature review, religious discrimination is more deeply rooted than other forms of discrimination (Akbaba \& Fox 2011). It should also be noted that respondents indicated the experience of moderate work engagement. Therefore it may be postulated that if a religious person understands their work as a calling, and in line with their purpose in life, they will experience work engagement, regardless of their experience of discrimination.
The results of the study should be interpreted with caution, for the following reasons. Firstly, the sample was drawn from Rastafari working in only two of the nine provinces of South Africa. Although the ideal would have been to include a sample of Rastafari working in all of the provinces of South Africa, it was not possible because of a lack of available data regarding Rastafari in South Africa. Secondly, a non-random sampling technique was used to generate the sample, which could have a negative influence on the external validity of the findings. However, the aim of the current study was to describe the occurrence of a phenomenon at a specific point in time in a well-defined sample. Hence, even though the results cannot necessarily be generalised to the larger population without caution, trends within the population could be identified for future empirical investigation. Thirdly, there is a paucity of academic literature regarding the Rastafari religion, and specifically Rastafari in South Africa. Therefore, it is important that the body of academic literature regarding this religious movement be expanded.

Until now, the relationship between perceived religious discrimination and work-related attitudes has not been studied. Thus, more research is needed to understand this complex relationship. For future research it would be interesting to investigate the above relationship from the perspective of different religious groups, particularly minority groups. Furthermore, previous research has found that perceived discrimination is a protective factor that is directly associated with positive outcomes, regardless of the degree of discrimination that the individual is exposed to (Reitmanova \& Gustafson 2008). Reitmanova and Gustafson (2008) report that religious identification buffers the relationship between exposure to discrimination and negative outcomes. Thus, it would be interesting to establish whether the relationship between perceived religious discrimination and work-related attitudes is moderated by religious identification and commitment.

The research reported on in this paper was ground breaking, in that this was one of the first studies worldwide to investigate the relationship between perceived religious discrimination and work engagement. Furthermore, it was the first study of its kind that specifically focused on the Rastafari religion. Consequently, the results of the current study could potentially provide additional insight into the influence of perceived religious discrimination on work-related attitudes, particularly work engagement. The findings of this study can be practically applied in the work environment, and they hold particularly important implications for organisational decision makers and human resource management practitioners, as well as organisational policies and practices. This is particularly so in light of the recent amendments to the EEA (RSA 2013), which aim to ensure stricter compliance with employment regulations, in order to eradicate unfair discrimination in workplaces in South Africa.

\section{Acknowledgements}

Language editing of this article was undertaken by Anthony Sparg. 


\section{Competing interests}

The authors declare that they have no financial or personal relationships which may have inappropriately influenced them in writing this article.

\section{Authors' contributions}

F.v.d.W. was the main supervisor and project leader, while T.S.M. collected the data and contributed towards the literature review. Additionally, the statistical analyses were performed by P.J.

\section{References}

Akbaba, Y. \& Fox, J., 2011, 'Religious discrimination against Muslim minorities in Christian majority countries: A unique case?', Politics, Religion \& Ideology 12(4), 449-470.

Amien, W., 2006, 'Overcoming the conflict between the right to freedom of religion and women's rights to equality: A South African case study of Muslim marriages', Human Rights Quarterly 28, 729-754.

Bakker, A.B., Albrecht, S.L. \& Leiter, M.P., 2011, 'Key questions regarding work engagement', European Journal of Work and Organizational Psychology 20, 4-28.

Barnett, M., 2012, Rastafari in the new millennium: A Rastafari reader, Syracuse University Press, New York.

Barnett, M., 2014, Rastafari in the new millennium: A Rastafari reader, 2nd ed. Syracuse University Press, New York.

Bayl-Smith, P.H. \& Griffin, B., 2014, 'Age discrimination in the workplace: Identifying as a late-career worker and its relationship with engagement and intended retirement age', Journal of Applied Social Psychology 44(9), 588-599.

Bodenhausen, G.V. \& Richeson, J.A., 2010, 'Prejudice, stereotyping, and discrimination', in R.F. Baumeister \& E.J. Finkel (eds.), Advanced social psychology: The state of the science, pp. 341-383, Oxford University Press, New York.

Bushman, B.J. \& Bonacci, A.M., 2004, 'You've got mail. Using email to examine the effect of prejudiced attitudes on discrimination against Arabs', Journal of Experimental Social Psychology 40, 753-759.

Calitz, T.M., 2013, 'An empowerment programme to regain positive work engagement for social workers in the North West Province', PhD (Social Work) thesis, NorthWest University, Potchefstroom.

Campbell, H., 1985, Rasta and resistance: From Marcus Garvey to Walter Rodney, Africa World Press, Trenton, NJ.

Chawane, M.H., 2012, 'The Rastafari movement in South Africa: Before and after apartheid', New Contree: A Journal of Historical and Human Sciences for Southern Africa 65, 163-188.

Chipangura, S., 2013, 'An investigation into the manifestation of stigma and discrimination and its consequences on HIV/AIDS prevention and treatment efforts amongst people living with HIV/AIDS', MPhil thesis, University of Stellenbosch, Stellenbosch.

Chughtai, A. \& Buckley, F., 2008, 'Work engagement and its relationship with state and trait trust: A conceptual analysis', Journal of Behavioural and Applied Management 10(1), 47-71.

Cottrell, C.A. \& Neuberg, S.L., 2005, 'Different emotional reactions to different groups: A socio-functional threat-based approach to prejudice', Journal of Personality and Social Psychology 88, 770-789.

Crozier-Fitzgerald, F., 2010, Rastafarian religious discrimination, viewed 31 January 2015, from http://archives.jrn.columbia.edu/2010-2011/thenewyorkworld.com/ 2015, from http://archives.jrn.columbia.ed
tag/francesca-crozier-fitzgerald/index.html

Ensher, E.A., Grant-Vallone, E.J. \& Donaldson, S.I., 2001, 'Effects of perceived job discrimination on job satisfaction, organizational commitment, organizational citizenship behavior, and grievances', Human Resource Development Quarterly 12(1), 53-72.

Fiske, S.I., Cuddy, A.J.C., Glick, P. \& Xu, J., 2002, 'A model of (often mixed) stereotype content: Competence and warmth respectively follow from perceived status and competition', Journal of Personality and Social Psychology 82(6), 878-902.

Fox, J., 2007, 'Religious discrimination: A world survey', Journal of International Affairs 61(1), 47-67.

Gee, G.C., Pavalko, E.K. \& Long, J.S., 2007, 'Age, cohort and perceived age discrimination: Using the life course to assess self-report age discrimination' Social Forces 86(1), 265-290.

Ghazarian, S.G., 2008, 'Perceived discrimination and academic achievement among Latino adolescents: A risk and resiliency model', PhD thesis, University of North Carolina, Greensboro, NC.

Ghumman, S., Ryan, A.M., Barclay, L.A. \& Markel, K.S., 2013, 'Religious discrimination in the workplace: A review and examination of current and future trends', Journa of Business and Psychology 28, 439-454.

Goosen, C.J., 2011, 'The impact of job and organisational characteristics on engagement at work in a petrochemical company', MBA thesis, North-West University, Potchefstroom.
Gordijn, E.H., Wigboldus, D. \& Yzerbyt, V., 2001, 'Emotional consequences of categorizing victims of negative outgroup behavior as ingroup or outgroup', Group Processes and Intergroup Relations 4, 317-326.

Grogan, J., 2011, Workplace law, 10th ed., Juta, Cape Town.

Harmse-Truter, L., 1998, 'Disability, discrimination and equal opportunities: A comparative labour law study', LLD thesis, University of Johannesburg, Johannesburg.

Hewstone, M., Rubin, M. \& Willis, H., 2002, 'Intergroup bias', Annual Review of Psychology 53, 575-604.

Hogg, M.A. \& Abrams, D., 1988, Social identification: A social psychology of intergroup relations and group processes, Routledge, London.

Horn, R., 2009, Researching and writing dissertations: A complete guide for business students, Chartered Institute of Personnel and Development (CIPD), London.

Jagusztyn, N.E., 2010, 'Perceived workplace discrimination as a mediator between work environment and employee outcomes: Does minority status matter?', PhD dissertation, University of South Florida, Tampa, FL.

Jasperse, M., Ward, C. \& Jose, P.E., 2012, 'Identity, perceived discrimination, and psychological well-being of Muslim immigrant women', Applied Psychology 61(2), $250-271$

Jonck, P., Le Roux, A. \& Hoffman, L., 2012, 'Parishioners' attitudes towards clergywomen: A South African case study', Journal of Theology for Southern Africa 144, 92-108.

Kahn, W.A., 1990, 'Psychological conditions of personal engagement and disengagement at work', Academy of Management Journal 33, 692-724.

Kassing, J.W., Piemonte, N.M., Goman, C.C. \& Mitchell, C.A., 2012, 'Dissent expression as an indicator of work engagement and intention to leave', Journal of Business Communication 49(3), 237-253.

Marumoagae, M.C., 2012, 'Disability discrimination and the right of disabled persons to access the labour market', Potchefstroom Electronic Law Journal persons to acces
$15(1), 345-428$.

Moifo, M.J., 2012, 'Indirect discrimination in the workplace: A comparison between South Africa and the United States of America', LLM (Labour Law) thesis, University of Limpopo, Polokwane.

Mxhakaza, J.N., 2011, 'Perceived discrimination of women in the mining sector', MBA thesis, North-West University, Potchefstroom.

Nelson, D.L. \& Quick, J.C., 2006, Organizational behavior: Foundations, realities and challenges, 5th ed., South-Western/Thomson, Mason, $\mathrm{OH}$.

Prince, G.A., 2001, v 'President of the Law Society of the Cape of Good Hope and Others', Constitutional Court, Cape Town, viewed 15 November 2014 from http:// Others, Constitutional Court, Cape Town, viewed 15
www.saflii.org/za/cases/ZACC/2000/28media.pdf

Reitmanova, S. \& Gustafson, D., 2008, “"They can't understand it": Maternity health and care needs of immigrant Muslim women in St. John's, Newfoundland', Maternal and Child Health Journal 12(1), 101-111.

Rice, J.K., 2009, 'The role of tenure as a moderator to work engagement and job satisfaction', MSc thesis, San José State University, San José, CA.

Richman, L.S., Pek, J., Pascoe, E. \& Bauer, D., 2010, 'The effects of perceived discrimination on ambulatory blood pressure and affective responses to interpersonal stress modeled over 24 hours', Health Psychology 29(4), 403-411.

Riordan, C.M., Schaffer, B.S. \& Steward, M.M., 2005, 'Relational demography within groups: Through the lens of discrimination', in R. Dipboye \& A. Colella (eds.),
Discrimination at work: The psychological and organisational bases, pp. 37-61, Discrimination at work:
Erlbaum, Mahwah, NJ.

RSA. 1995, Labour Relations Act, Act 55 of 1998, Government Printers, Pretoria.

RSA. 1996, Constitution of the Republic of South Africa, Act 108 of 1996, Government Printers, Pretoria.

RSA. 1998, Employment Equity Act, Act 55 of 1998, Government Printers, Pretoria. RSA. 2013, Employment Equity Act, Act 47 of 2013, Government Printers, Pretoria.

Salkind, J.N., 2012, Exploring research, 8th ed., Pearson Education, Boston.

Schaufeli, W.B., Salanova, M., González-Romá, V. \& Bakker, A.B., 2002, 'The measurement of burnout and engagement: A two sample confirmatory factor analytic approach', Journal of Happiness Studies 3, 71-92.

Schaufeli, W.B., Taris, T.W. \& Bakker, A.B., 2008, 'It takes two to tango. Workaholism is working excessively and working compulsively', in R.J. Burke \& C.L. Cooper (eds.),
The long work hours culture. Causes, consequences and choices, pp. 203-226, The long work hours

Sibisi, S.C., 2012, 'Occupational stress, job satisfaction, work engagement and the mediating role of social support among nurses at a public hospital in Durban', MSocSc thesis, University of KwaZulu-Natal, Durban.

Sonnentag, S., 2011, 'Research on work engagement is well and alive', European Journal of Work and Organizational Psychology 20(1), 29-38.

Storm, K., 2002, 'Burnout and work engagement in the South African Police Service', Doctoral thesis, Potchefstroom University for Christian Higher Education, Potchefstroom.

Tajfel, H., 1972, 'Experiments in a vacuum', in J. Israel \& H. Tajfel (eds.), The context of social psychology, pp. 69-119, Academic Press, London.

Tajfel, H. \& Turner, J.C., 1979, 'An integrative theory of intergroup conflict', in W.G. Austin \& S. Worchel (eds.), The social psychology of intergroup relations, pp. 7-24, Brooks-Cole, Monterey, CA.

Tesfaye, Y., 2010, 'The effect of discrimination on job performance and job satisfaction', BA Honours dissertation, University of Wolverhampton, Wolverhampton.

Thomas, K.M. (ed.), 2008, Diversity resistance in organisations, Taylor \& Francis Group, LLC, New York. 
Thompson, J., 2012, 'From Judah to Jamaica: The Psalms in Rastafari reggae', Religion and the Arts 16(4), 328-356.

Trottman, M., 2013, Religious discrimination claims on the rise, viewed 30 March 2014, from http://www.wsj.com/articles/SB10001424052702304682504579153 462921346076

Turner, J.C., 1983, 'The measurement of social orientations in the minimal group paradigm', European Journal of Social Psychology 13, 351-367.

Van der Walt, F., 2007, 'The relationship between spirituality and job satisfaction', $\mathrm{PhD}$ thesis, University of Pretoria, Pretoria.
Walt, A., 2002, 'Age discrimination in labour law: A comparative inquiry', LLM dissertation, Rand Afrikaans University, Johannesburg.

Webley, S., 2011, Religious practices in the workplace, Institute of Business Ethics, London.

Wilder, D.A., 1986, 'Cognitive factors affecting the success of intergroup contact', in S.W. Worchel \& W.G. Austin (eds.), Psychology of intergroup relations, pp. 49-66, Nelson-Hall, Chicago, IL.

Williamson, J.C., 2011, 'Engagement and meaningfulness at work: The moderating role of life satisfaction and gender', MCom dissertation, University of Johannesburg, Johannesburg. 